\title{
Introduction from the Editor
}

Welcome to the second issue in the tenth volume of the International Journal of Housing Markets and Analysis. Notably, this is the tenth anniversary issue of the journal which has now expanded to five issues per year, with future intentions to continue to expand to meet the increasing submission levels of high quality research. The seven papers in this issue examine areas of housing research which are globally relevant and make a meaningful contribution to knowledge.

The first paper examines the impact of neighbourhood design templates on residential home values in the USA. The study examined over 27,000 house sales and used a hedonic model to measure the impact across three large regional submarkets where neighbourhood design categories are developed using a cluster analysis on a set of individual neighbourhood attributes. The findings show that the impact of more traditional design packages on home values is highly contextual, where more traditional design results in a significantly positive impact on home values for older and denser neighbourhoods in the study area. The second paper from Hong Kong used quarterly data to examine the cointegration and causality relationships between Hong Kong's residential property prices and stock prices between 1980 (Q1) and 2015 (Q3). The results provide strong evidence to support the hypothesis that residential property prices and stock prices are cointegrated. The results also support the argument regarding wealth effect that stock price has an important causal effect upon residential property price in Hong Kong but not vice versa. Furthermore, the results of recursive OLS coefficients estimates and breakpoint test for structural instability confirm the variation of the relationships between stock and residential property markets over the sample period.

The third paper examined the New Zealand market with reference to high voltage overhead transmission lines (HVOTLs) and their relationship with housing values. The results provided important inside into the effect of removing the HVOTLs; for example, it was shown that prior to the removal of the HVOTLs, there was a negative sale impact of 27 per cent on properties adjacent to the towers, which reduced to 5 per cent at a distance of 50 metres and also had a negligible impact from 100 metres. The paper also discussed further analysis that was conducted and provides insightful evidence about the market operation with reference to HVOTLs.

The fourth paper from Germany considers to what extent tourism affects the level of rent in Berlin. The aim of the study is to undertake an innovative study by quantifying the impact of urban tourism on the housing market; this is undertaken by measuring the spatial effect of tourism hotspots on housing rents in Berlin. The findings confirmed that UTH (i.e. tourist attractions, restaurants, hotels and holiday flats) affected rental of surrounding flats and that the four different types of UTH cause different effects, largely depending on the type of model and its functional form. In addition, there are additional findings which are also relevant for policy-makers and urban planners.

The fifth paper investigated influencing factors which could possibly motivate homeowners to change their expected holding horizons for residential property in the USA. The findings confirmed that in addition to the financial characteristics of recent homebuyers, the characteristics associated with the buying experience (i.e. non-monetary, such as the realized search duration, and monetary, such as perception of negative or positive premium paid for the house relative to its market value) have a statistically significant effect on the holding horizon. The findings also show the perception of having overpaid increases the likelihood of upward 
revision of the original holding horizon. Importantly, it was observed that this effect is stronger in a declining market than in a rising market.

Editorial

The sixth paper from Hong Kong investigated the main drivers affecting house where there was an analysis of the potential for over-valuation of house prices which may have influenced the existence of a "bubble" scenario. The data analysis focused on decomposing house prices during the period from 1993 (Q3) to 2013 (Q3) where the findings indicated there could be a possible correction of up to 46 per cent of house prices with reference to the 2013 (Q3) level.

The final paper examined the housing market in Australia and analysed the linkages between Australian house prices and stock prices under the Toda and Yamamoto test frameworks. In addition, it investigated the potential existence of a capital switching effect between housing prices and stock prices. The findings confirmed a negative lead-lag relationship between house prices and stock prices, suggesting the existence of capital switching activities between housing and stocks. The impact of the global financial crisis (GFC) on the lead-lag relationship between house prices and stock prices was also observed. In addition, prior to the GFC a causality transmission was observed between house prices and stock prices; however, stock prices appeared to lead house prices after the crisis. Furthermore, the capital switching activities between housing and stocks were more evident for small cap stocks.

These research papers have all passed a rigorous double-blind refereeing process and make a substantial contribution to the existing literature. If I can be of assistance prior to submission and discuss the procedure for admission into the review process, please contact me directly. In addition, if you have any comments or are interested in submitting a research paper or reviewing potential publications, please contact the editor direct at: ijhma@ijhma.com

Richard Reed

Faculty of Business and Law, Deakin University, Melbourne, Australia 